\title{
Neurodynamic Mobilization and Peripheral Nerve Regeneration: A Narrative Review
}

Herman Henrique Silva Santana ${ }^{1,2}$, lasmyn Adélia Victor Fernandes de Oliveira ${ }^{1,2}$, Êmyle Martins Lima ${ }^{1,2}$, Alena Ribeiro Alves Peixoto Medrado ${ }^{3,4}$, Katia Nunes Sá ${ }^{5}$ Ana Maria Blanco Martinez ${ }^{6 \#}$, Abrahão Fontes Baptista ${ }^{1,2^{*}}$

${ }^{1}$ Post-graduation Program on Medicine and Health, Faculty of Medicine, Federal University of Bahia, Rua Augusto Viana, s/n Hospital Universitário Prof. Edgard Santos, 5oandar, Canela, 40.110-060, Salvador, BA, Brazil

${ }^{2}$ Functional Electrostimulation Laboratory, Biomorphology Department, Federal University of Bahia, Av. Reitor Miguel Calmon, s/n, sala 306, Vale do Canela, 40.110-902, Salvador, BA, Brazil

${ }^{3}$ Gonçalo Moniz Research Center - Oswaldo Cruz Foundation (FIOCRUZ), Rua Waldemar Falcão, Candeal, 40.296-710, Salvador, BA, Brazil

${ }^{4}$ Bioregulation Department, Federal University of Bahia, Av. Reitor Miguel Calmon, S/N, Vale do Canela, 40.110-902, Salvador, BA, Brazil

${ }^{5}$ Bahian School of Medicine and Human Health, Av. D. João VI, 275, Brotas, 40.290-000, Salvador, BA, Brazil

${ }^{6}$ Neurodegeneration and Repair Laboratory, Department of Pathology, Faculty of Medicine, Federal University of Rio de Janeiro, Av. Pedro Calmon, Cidade Universitária, 21941-901, Rio de Janeiro, RJ, Brazil. Phone.: +55 21 3938-6431

"Corresponding author: Abrahão Fontes Baptista, Laboratório de Eletroestimulação Funcional, Instituto de Ciências da Saúde, UFBA - Av. Reitor Miguel Calmon, s/n Vale do Canela Salvador, BA, Brasil 40.110-902, Tel: +55 71 3283-8888; E-mail: afbaptista@ufba.br

Rec date: Mar 25, 2015; Acc date: May 27 2015; Pub date: June 03, 2015

Copyright: (c) 2015 Santana HHS, et al.This is an open-access article distributed under the terms of the Creative Commons Attribution License, which permits unrestricted use, distribution, and reproduction in any medium, provided the original author and source are credited.

\#Both authors advised this study

\begin{abstract}
After a peripheral nerve injury, various aspects, including mechanical nerve properties, will influence regeneration. The reduction of nerve viscoelasticity, intraneural edema, mechanosensitivity, and adhesion of neural tissue to its interfaces may be a target to approaches that impose graded mechanical loads to the nerve. However, the effects of those treatments on peripheral nerve regeneration are not clear. Particularly neurodynamic mobilizations may be very useful. They consist of therapeutic maneuvers to assess nerve mechanical properties and restore their function through graded movements of the peripheral nerve attachments to bones and muscles. Here we discuss theoretical and experimental data regarding the effects of graded mechanical loads on peripheral nerve function and regeneration, and propose how neurodynamic mobilizations would interact with the peripheral nerve in order to promote regeneration. Those effects would influence the reduction of edema, normalization of axoplasmic flow, decrease nerve mechanosensitivity, and promotion of appropriate nerve mobility, increasing glial and neuronal activity.
\end{abstract}

Keywords: Peripheral Nerve Regeneration; Neurodynamic Mobilization; Mechanical Load; Nerve; Biomechanics

\section{Introduction}

Peripheral nerves may have their normal function disturbed by traumatic, metabolic and/or immune injuries, that lead in general to flaccid paralysis or paresis, sensory disturbances, pain and autonomic dysfunction[1]. As consequences a series of changes will occur in their target organs, such as muscles and vessels [2]. Those changes are not only peripheral, but also happen in the central nervous system, including the spinal cord and the brain [3-5].

Anatomically, the peripheral nervous system is complex, being composed of hundreds to thousands of nerve cells surrounded by biologic tissue layers. Peripheral nerve trunks connect the brain and spinal cord to all muscles, glands, blood vessels and other body structures by means of motor (somatic or autonomic) and sensory neurons. The structure of the peripheral nerve trunk is unique and dramatically different from the brain and spinal cord. Peripheral nerve cells are involved by three layers of connective tissue, epi, peri and endoneurium [6]. Among other functions, these layers provide mechanical properties to the peripheral nerve.
When the nervous system is in dysfunction, its mechanical properties are also affected $[7,8]$. The understanding of this specific pathomechanic behavior is essential for a number of disciplines, but surgery and physiotherapy are the ones that most directly deal with these changes. After a traumatic compression injury there is an inflammatory reaction associated with edema, which increases mechanical stress imposed to the peripheral nerve. There is consequent increase in nerve sensitivity, resulting in the presence of signs and symptoms frequently seen in nerve entrapment syndromes such as carpal and tarsal tunnel syndromes, and piriformis syndrome [7-10]. When the trauma results in nerve transection, surgery is mandatory with a dramatic impact on peripheral nerve mechanics. Soon after lesion and/or surgery, stress on the nerve should be avoided in order to prevent pathological tension and disruption of the suture. However, if immobilization is maintained for a long time, lack of movement and adequate mechanical load may lead to nerve adhesion to adjacent layers, poor drainage of endoneurial edema, fibrosis and permanent dysfunction of the peripheral nerve [11-13].

One of the physiotherapeutic goals after peripheral nerve injuries is to maintain adequate movement between the nerve and its anatomical interfaces [14]. A series of maneuvers - Neurodynamic Mobilization (NM) may be used to impose specific tension to individual nerves, nerve trunks and plexus. If symptoms are reproduced, these 
maneuvers can be used to restore adequate mechanical properties $[15,16]$. However, although there is a growing understanding on how mechanical stress influences biological tissues [17] and how these maneuvers can be used in the diagnosis and treatment of disorders of the peripheral nervous system, curiously there is quite poor evidence on how they affect peripheral nerve regeneration. Understanding this phenomenon is of fundamental importance in the recovery of motor, sensory and autonomic functions, after the lesion [18]. Therefore the aim of this study is to review the literature on the influence of mechanical loads applied to peripheral nerves on its physiology and regeneration after lesion. We also highlight the lack of experimental studies involving the effects of graded mechanical loads neurodynamic mobilization on peripheral nerve regeneration, suggesting some mechanisms by which these maneuvers would act therapeutically to enhance regeneration.

\section{Methodology}

Articles to compose the main section of this review (mechanical loads and nerve regeneration) were tracked in PubMed, using the keyterms Peripheral Nerve Injuries, Peripheral Nerve Regeneration, Neurodynamic Mobilization, Mechanical Load and Nerve Biomechanics. There were no limits of language or year of publication. Included studies involved either laboratory animals or human samples (including cadavers) where the influence of mechanical loads on peripheral nerve physiology and/or regeneration was assessed.

\section{Results}

The first results of this search found 2159 articles, which had their titles and abstracts read to exclude those, which did not involve the objective of the study. This resulted in 202 articles, which were read to identify their results regarding the influence of mechanical loads on peripheral nerve regeneration. From these articles were included in this review 70 (Figure 1).

\section{Discussion}

\section{Axons, Schwann cells, myelin sheath and axonal transport can be influenced by mechanical loads}

The axons of intact and mature peripheral nerves comprise the axoplasm, which contains a scaffold of organelles and proteins consisting of microfilaments, intermediate neurofilament proteins and microtubules. The axons are enveloped by the plasma membrane, called axolemma. Microfilaments are found in subaxolemal cytoskeleton, while neurofilaments and microtubules are distributed throughout the axon [19].

Schwann cells (SC) are recognized in vivo at the ultrastructural level by its close association with axons. By electron microscopy, its core is described as pale, without condensation or nuclear irregularities. Most have pale cytoplasm with a minority (less than 5\%) with dark cytoplasm, and most do not have prominent organelles [6]. The basal membrane of the SC is easily recognized by electron microscopy as an irregularly distorted material outside of the plasma membrane.

It can be divided into two layers known as the lamina densa (dense area) and an inner lamina lucida (free space), being composed of type IV collagen, laminin and fibronectin. SC mediate nerve adaptation to gradual lengthening of a member through the expression of TNFalpha [20]. Low elongation rates allow the nerves to fit to the increase of the internodal distance [21], and elongation of the SC [22]. This behavior allows the peripheral nerves to grow during normal development and also when submitted to stretching.

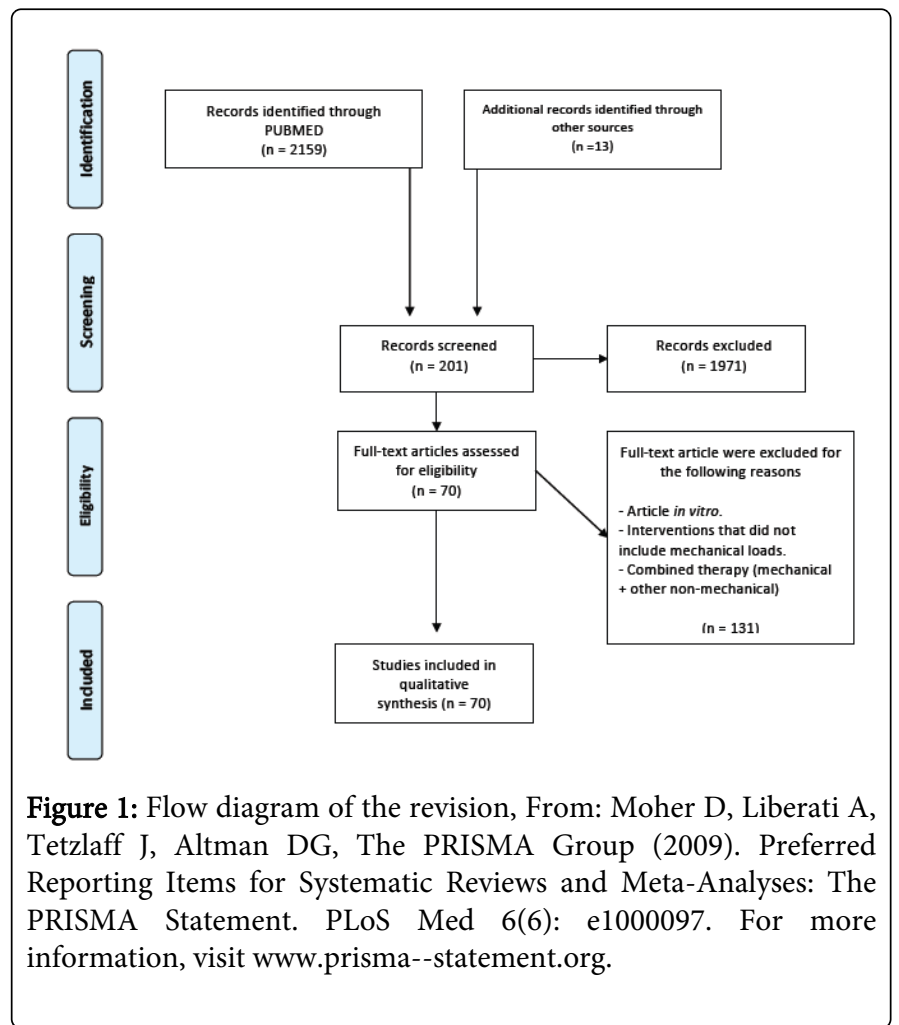

The myelin sheath consists of a lipid membrane, which is synthesized by SC in the Peripheral Nervous System (PNS) and oligodendrocytes in the central nervous system. The myelination of the PNS involves the spiraling of the CS membranes around axons to form sheaths or lamellae. The number of lamellae is a function of the diameter of the axon [19]. In general, the myelin is composed of about $70 \%$ of lipids, and $30 \%$ of proteins.

Axons and CS, among other cells, have an intimate relationship with the endoneurium and are also susceptible to mechanical loads. Changes in the myelin sheath, modification of the structure of the Ranvier node and reduction of sodium channels density are some of the reactions of these structures to excessive mechanical loads. Jou and collaborators [23] found reversible conduction blocks in nerves submitted to $8 \%$ of strain. In $50 \%$ of these nerves the conduction became irreversible after $16 \%$ of strain. It is possible that the stretch of the node of Ranvier, changed its wavy characteristic and impaired impulse transmission [23-25].

Finally, neuronal function is closely related to the synthesis of proteins and axonal transport, which are complex phenomena not fully understood [26]. An abnormal axonal transport can start a cycle of degeneration and cell death [27-29]. After a peripheral nerve injury, signaling via retrograde axonal transport is responsible for initiating the cascade responsible for the degeneration and subsequent nerve regeneration, when possible $[30,31]$. If this transport is insufficient or inaccurate, there will be prejudice to the repair process. Thus axonal transport is a major target when the goal is to stimulate peripheral nerve regeneration [32]. Although not clearly determined yet, it is possible that neurodynamic maneuvers may increase axonal transport and positively influence peripheral nerve regeneration. Another 
possibility is that nerve stress itself may be a conditioning lesion, which is able to increase the regenerative process [33].

\section{Nerve biomechanics and pathomechanics}

The presence of structures that respond to mechanical loads in the peripheral nervous system makes the biomechanics and pathomechanic important aspects to be considered both in normal, and in pathological conditions. However, in most cases the nerve biomechanics studies discuss only extreme situations, such as a gradual nerve stretching during limb elongation or in surgical conditions. Conversely, the majority of mechanical loads are imposed on the nerves by posture, movements and mild trauma [34]. However, there is a lack of experimental data on nerve biomechanics in these circumstances, and the majority of our understanding about this topic comes from studies approaching structural properties such as nerve anatomy, or experimental data from laboratory animal trials.

Biomechanical properties of the peripheral nerves are conferred mainly by the presence of collagen tissue and liquids. Because of the diversity of collagen types composing the epi, peri and endoneurium, peripheral nerves have a viscoelastic characteristic that allows resisting to mechanical loads, such as changes in length, compression and traction. The resistance to traction is more characteristic of peri and endoneurial layers, while the epineurium is more resistant to compressive forces $[35,36]$. This is because the response to mechanical traction occurs from the inner to the outermost layers, while in compression, the opposite happens. This means that the tensile mechanical loads will affect mainly the deepest structures in the peripheral nerves [37]. Studies in sciatic nerves of rats have demonstrated that, when submitted to mechanical tension, nerve structure starts to fail at the perineurium, followed by the axons and endoneurium, and finally the epineurial sheath $[38,39]$.

The interaction with adjacent tissues also allows peripheral nerves to adapt to the imposed shear and compression forces, stretching, repeated stresses and combinations of these different types of mechanical loadings [40]. The elongation or tensile loads can be applied in parallel or perpendicular to the nerve, causing longitudinal or transverse forces. When joint movement stretches the nerve surrounding tissues, the nerve itself is placed under tension and reacts to stress both lengthening as sliding [41]. The deformation or change in nerve length induced by longitudinal stress is called tension stress. When there is displacement or sliding over the nerve bed, this movement is called excursion, in other words there is dislocation of the nerve from one point to another [41].

Traction can also cause nerve excursion and simultaneously produce changes in pressure within the nerve. The elongation of the nerve bed during joint movement will cause an increase in tension [37]. The magnitude of the increase in pressure will be higher as close as the nerve is from the moving joint. The tissue response is dependent on the magnitude and duration of the mechanical load. Data indicate that elongations of $6 \%$ to $8 \%$ for a short period causes transitional physiological changes that appear to be within normal tissue tolerance, while $11 \%$ or more causes long-term damage and may be regarded as a state of excessive or extreme tension [42].

Compression or crushing is another way of influencing nerve physiology through mechanical loads. Compressing a nerve may be the result of extraneural force or can occur secondarily by increasing the longitudinal tension [43]. Compressive loads of low magnitude and short duration can result in reversible structural and physiological changes. However, high magnitudes of compression may result in structural changes in myelin sheaths, and axons, and even rupture of the nerve [40]. This can also happen with low magnitude loads only if applied over a long period of time. In this case the structural changes in the nerve will be secondary to insufficiency of blood irrigation and the consequences of ischemia.

Mechanical loads can also influence nerve physiology and response to lesion by other ways such as progenitor cells, neuronal migration, axon elongation, synaptogenesis and developing of neural networks [44-46]. All these factors are fundamental in peripheral nerve regeneration, and would place neurodynamic mobilization as a way to influence not only structural, but functional properties of peripheral nerves (Figure 2).

\section{Peripheral nerve injury and regeneration}

Peripheral nerve injuries are common, disabling and difficult to treat, varying widely in the extent and severity of the injury. The nerves are exposed to various types of lesions including compression, crushing and transection. The type of injury also has a major influence on functional recovery. The simplest peripheral nerve injury classification was provided by Seddon, who grouped the lesions in neurapraxia, axonotmesis and neurotmesis $[11,47]$.

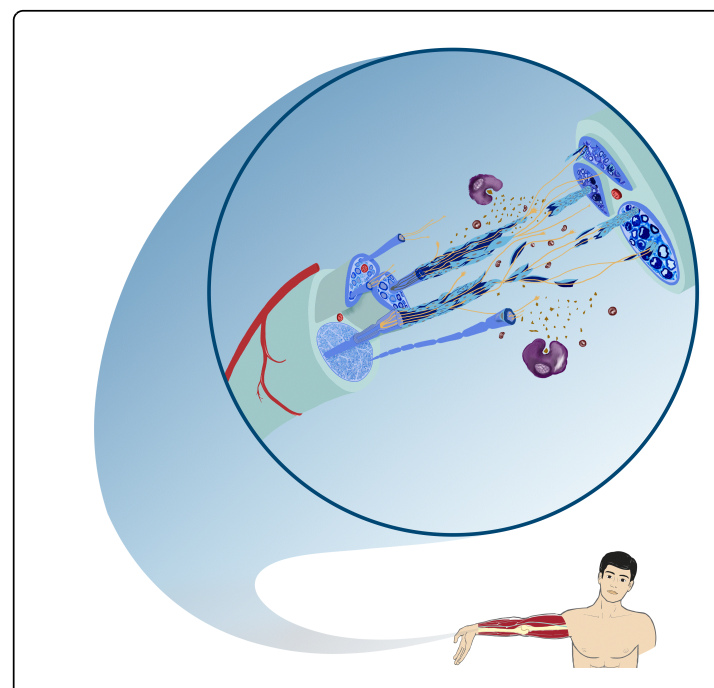

Figure 2: Damaged nerve submitted to mechanical loads will react according to many factors, including the lesion degree and mechanical properties of the nerve itself.

In neurapraxia there is no loss of axonal continuity between the neuron and the innervated structure. There is only block of nerve conduction as a consequence of myelin sheath damage. This injury involves the inability of an action potential to propagate beyond a specific region of the axon, and an important aspect is its reversibility $[11,48]$. The conduction block usually affects motor fibers more than sympathetic or sensory fibers, and a typical example is the "Saturday night palsy"[11]. This lesion involves prolonged compression of the radial nerve on the forearm by a chair or the head of a friend. Another example is the common peroneal nerve compression, which happens when the legs are kept crossed for long periods. The consequences are temporary, with no histological change. However, as the compressive force persists, there is demyelination and, subsequently, remyelination at the site of lesion [49]. 
In axonotmesis, axons are affected and shortly after there is axonal injury. The proximal portion of the axon suffers traumatic degeneration in the damaged area, and the death of the cell body itself may occur, depending on the mechanism and severity of the injury. The collapse of the distal axon (Wallerian degeneration) is started 30 to 96 hours after transection. The deterioration of myelin begins and the axon becomes disorganized. The progression is completed about one week after the beginning of the injury [50].

The retrograde reaction leads the cell body to swell. There is chromatolysis, a process in which granules Nissl (endoplasmic reticulum of groups and free ribosomes) is fragmented and the cell body becomes relatively eosinophilic. The cell nucleus is displaced to the periphery, which reflects a metabolic change. At the same time there is the onset of the regenerative events, with an increased expression of proteins to assist in the repair and axonal growth. Schwann cells proliferate and phagocyte axonal and myelin debris. Nerve damage may disrupt the blood-nerve barrier. In this phase there is an increase in size and number of glial cells, which starts at 24-48 and reaches its peak in a week [51].

Neurotmesis refers to an injury of the whole nerve trunk, including connective tissues. The epineurium is damaged, therefore separating the proximal from the distal stump. All changes resulting from an axonotmesis occur in the same way in neurotmesis. The difference between them is that the prognosis of the injury is much worse, the retrograde changes are much more serious, and the majority of the neurons do not survive. Furthermore, the spaces between the two segments of the sectioned nerve can be blocked by fibrosis, and this may pose a major obstacle in nerve regeneration [48].

Chronic compression of the peripheral nerves are another form of injury; different from stretching injuries, acute compressions [52] and transections, they start with compressive external mechanical loads that generate intraneural edema, and gradually there is reduced flow in the vessels supplying the nerve (Vasa nervorum). There is a local ischemia, which has an immediate effect on the ability of axons to transmit action potentials. As the compression becomes more severe there is demyelination, followed by axonal damage, scarring and fibrosis. Fibrosis in turn affect the nerve movement over its bed, creating adhesions to surrounding tissues [53,54]. The effect of compression may be exacerbated when the nerves are in osteofibrous tunnels, generating compressive neuropathies such as carpal tunnel syndrome and sciatic nerve compression [55].

After the degeneration Schwann cells start to align longitudinally to the nerve, creating columns of cells called Büngner bands that provide a favorable microenvironment for growth promotion and regenerating axons. There is shrinking of endoneurial tubes, and Schwann cells and macrophages fulfill their ends. At the tip of the regenerating axon there are the growth cones, with the capacity to explore the microenvironment and for that they equipped with specialized mobility. The growth cone consists of flat sheets of matrix structure, called lamelopodia, from which a number of finger-like projections called filopodia, protrude and exploit the microenvironment [56].

The filopodia are electrophilic and attach themselves to cationic regions of the basal lamina. Within filopodia are actin filaments, which are able to produce axonal elongation and contraction. Growth cones release proteases that dissolve the extracellular matrix to clear the way and move on towards the target organ [51].

The growth cone responds to neurotrophic factors that are macromolecular proteins in sensory receptors. Schwann cells along the regeneration path also release these factors. These factors help in survival, length and maturation of regenerating axon. Fibronectin and fibrinogen are precursors of matrix formation these are polymerized to form a fibrin matrix, which is an important substrate for cell migration in nerve regeneration [6].

Axons growing in a stable condition take 8-15 days to reach the endoneurial tubes. When they finally reach the distal region of the endoneurial tube containing the Schwann cells, alignment arises between them and it starts a rotation movement around the axon to form the myelin sheath. With myelination there is a larger number of nodes of Ranvier, causing shorter internodal segments. The growth rate varies from nerve to nerve. The median grows $2-4 \mathrm{~mm} /$ day, ulnar $1.5 \mathrm{~mm} /$ day and radial, $4.5 \mathrm{~mm} /$ day. On average, the regeneration speed is $1 \mathrm{~mm} /$ day [57].

\section{Role imposing graduated mechanical loads (neurodynamic mobilization) in peripheral nerve regeneration}

We propose that the neurodynamic mobilization could positively influence the peripheral nerve regeneration through the following mechanisms: a) Reduction of edema; b) Normalization of axoplasmatic flow; c) Decrease in abnormal nerve mechanosensitivity, with consequent reduction of hyperalgesia and neurogenic inflammation; d) Promotion of appropriate nerve mobility, reducing susceptibility to trauma; e) Increased neuronal and glial activity (Schwann cells) through stimulation of movement dependent receptors in the cell membrane.

The neurodynamic maneuvers can be classified into two types, the tensioners and sliding (Figure 3). In the former, the aim is to impose pressure on the nerve structure, which is achieved from movements in body segments that increase the distance from fixation sites of the nerves. If we take into account the median nerve and its attachments in the brachial plexus and carpal tunnel, in a tensioning maneuver the fist would be extended, while the neck would be tilted to the other side of the mobilized segment [58] (Figure 3). Sliding maneuvers, on the contrary, will promote alternate movements in these attachment regions so that the nerve structure would be conducted to slide over its bed. Using the previous example, the neck and the fist would be moved simultaneously, but with extension of the fist, the head would move at the same time ipsilaterally [58]. (Figure 3) 

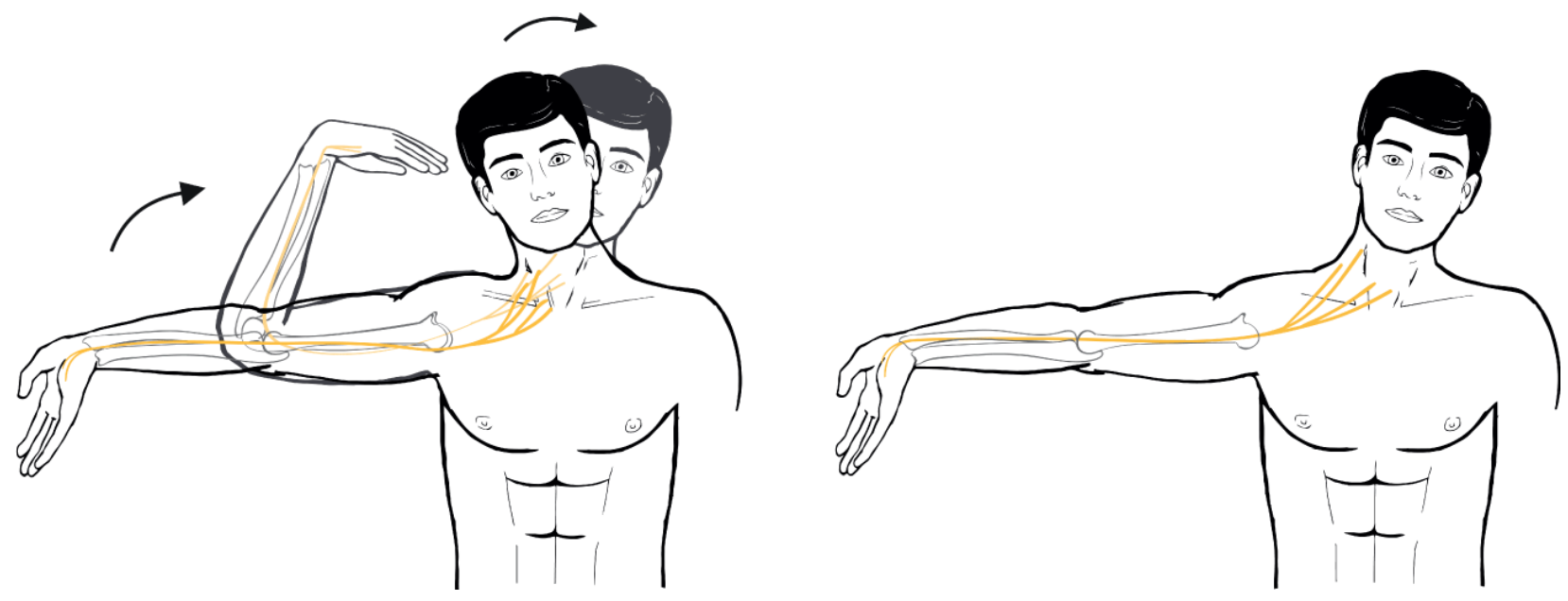

Figure 3: Neurodynamic Mobilization can be either, sliding (left) or tensioning (right), depending on the synchronization of limbs and axial movements. In this illustration, upper limb and neck/head can move in the same or opposite directions.

As intraneural edema is an important factor in peripheral nerve injury [59] and the swelled nerve is more subject to compressive lesions [53], the sliding maneuvers would probably be more beneficial in the acute phase, allowing the nervous drainage and increasing axoplasmatic flow by means of oscillatory movements. Moreover, these maneuvers would prevent the increase in intraneural pressure that could compress the nerve fibers and reduce neural irrigation, leading to ischemia and conduction block.

In the chronic phase, especially in lesions that underwent surgery, intraneural fibrosis may be a factor to limit its normal functioning. In this case the tensioners maneuvers would have an important role in promoting a gradual increase in the length of Scwhann cells body and internodes [60]. Since in this situation the risk of axonal injury would be higher due to increased pressure intrafascicular, control of symptoms during the mobilization would be mandatory to establish optimal loads.

The movement disorders in peripheral nerves seem to be accompanied by increased mechanosensitivity [61-63], although this phenomenon is not unanimous [64]. Recent concepts of the gate control theory of pain control support that non-aggressive movement may lessen the pain $[65,66]$. Both sliding and tensioning maneuvers made prior to the amplitude of pain could reduce the mechanosensitivity via Nervi nervorum - the innervation of the nerve. An appropriate and perception control of symptoms during the intervention could be guide the treatment dose. Similar maneuvers but actively performed by the individual should be included to enhance the effect of treatment.

Although evidence from experimental studies occasionally argues against the use of mechanical loads to promote peripheral nerve regeneration [67], detailed monitoring of motor, sensory and autonomic symptoms can enable a treatment focused on the individuality of the patient and support or not its continued use. The understanding of normal nerve mechanics can also help people to avoid positions and postures that can be a source of peripheral nerve injury or surgical sutures disruption, preventing damage caused by excessive stresses $[68,69]$. Mobilization can also promote greater specificity in the motor reinnervation, increasing the number of regenerated axons and decreasing the expression of glial proteins linked to degeneration and pain [70].

Future studies may be addressed to fulfill a number of gaps in this area, including the assessment of the impact of Nerve Mobilization on axonal transport, edema formation and drainage, fibrosis formation and abnormal mechanosensitivity. Although studies with laboratory animals may offer relevant basic data, joining nerve tensioning maneuvers with a number of resources such as ultrasound and magnetic resonance imaging and electrophysiological testing of the peripheral nerve can help to clarify what happens in different diseases involving nerve degeneration/regeneration and abnormal biomechanics in humans. These diseases include, but are not restricted to, grade III carpal tunnels syndrome, diabetic and leprosy neuropathy and sutures of damaged peripheral nerves. Correlations between biomechanical limitations, signs and symptoms, imaging and electrophysiological testing may help to establish when Neurodynamic Mobilization will or not be a good alternative to positively influence nerve regeneration.

\section{Conclusion}

The peripheral nerve has a normal mechanical behavior that is altered in the presence of lesions. Maneuvers that impose gradual mechanical loading may be beneficial to promote peripheral nerve regeneration via a series of mechanical and physiological factors. Excessive mechanical stress can be deleterious, but an adequate clinical follow-up can help prevent such effects. This follow-up may include the use of neurodynamic tensioning maneuvers together with imaging and electrophysiological techniques, in order to identify when and how neurodynamic mobilization should or not be used to positively influence nerve regeneration.

\section{Acknowledgment}

This study was funded by CAPES, CNPq and FAPESB. 


\section{References}

1. Lundborg G (2004) Nerve Injury and Repair - Regeneration, Reconstruction and Cortical Remodeling. Elsevier.

2. Stoll G, Müller HW (1999) Nerve injury, axonal degeneration and neural regeneration: basic insights. Brain pathology (Zurich, Switzerland) 9:313-325.

3. Navarro X (2009) Chapter 27: Neural plasticity after nerve injury and regeneration. Int Rev Neurobiol 87: 483-505

4. Davis KD, Taylor KS, Anastakis DJ (2011) Nerve injury triggers changes in the brain. Neuroscientist 17: 407-422.

5. Taylor KS, Anastakis DJ, Davis KD (2009) Cutting your nerve changes your brain. Brain 132: 3122-3133.

6. Zochodne DW (2008) Neurobiology of Peripheral Nerve Regeneration. Cambridge University Press, Cambridge.

7. Mackinnon SE (2002) Pathophysiology of nerve compression. Hand Clinics 18:231-241.

8. Keir PJ, Rempel DM (2005) Pathomechanics of peripheral nerve loading Evidence in carpal tunnel syndrome. J Hand Ther 18: 259-269.

9. Dahlin LB (1991) Aspects on pathophysiology of nerve entrapments and nerve compression injuries. Neurosurg Clin N Am 2: 21-29.

10. Lundborg G, Dahlin LB (1996) Anatomy, function, and pathophysiology of peripheral nerves and nerve compression. Hand Clin 12: 185-193.

11. Lee SK, Wolfe SW (2000) Peripheral nerve injury and repair. The Journal of the American Academy of Orthopaedic Surgeons 8: 243-52.

12. Griffin JW, Hogan MV, Chhabra AB, Deal DN (2013) Peripheral nerve repair and reconstruction. J Bone Joint Surg Am 95: 2144-2151.

13. Isaacs J (2013) Major peripheral nerve injuries. Hand Clin 29: 371-382.

14. Novak CB, von der Heyde RL (2013) Evidence and techniques in rehabilitation following nerve injuries. Hand Clin 29: 383-392.

15. Schmid AB, Brunner F, Luomajoki H, Held U, Bachmann LM, et al. (2009) Reliability of clinical tests to evaluate nerve function and mechanosensitivity of the upper limb peripheral nervous system. BMC Musculoskelet Disord 10: 11.

16. Schmid AB, Nee RJ, Coppieters MW (2013) Reappraising entrapment neuropathies--mechanisms, diagnosis and management. Man Ther 18: 449-457.

17. Mueller MJ, Maluf KS (2002) Tissue adaptation to physical stress: a proposed "Physical Stress Theory" to guide physical therapist practice, education, and research. Physical therapy 82:383-403.

18. Wang Y, Sunitha M, Chung KC (2013) How to measure outcomes of peripheral nerve surgery. Hand Clin 29: 349-361.

19. Fitzgerald MJT, Gruener G, Mtui E (2007) Clinical Neuroanatomy and Neuroscience. 428.

20. Hagiwara N, Ikeda K, Higashida H, Tomita K, Yokoyama S (2005) Induction of tumor necrosis factor-alpha in Schwann cells after gradua elongation of rat sciatic nerve. Journal of Orthopaedic Science10:614-621.

21. Abe I, Ochiai N, Ichimura H, Tsujino A, Sun J, et al. (2004) Internodes can nearly double in length with gradual elongation of the adult rat sciatic nerve. J Orthop Res 22: 571-577.

22. Yokota A, Doi M, Ohtsuka H, Abe M (2003) Nerve conduction and microanatomy in the rabbit sciatic nerve after gradual limb lengthening Distraction neurogenesis. Journal of Orthopaedic Research 21:36-43.

23. Jou IM, Lai KA, Shen CL, Yamano Y (2000) Changes in conduction, blood flow, histology, and neurological status following acute nervestretch injury induced by femoral lengthening. Journal of Orthopaedic Research 18:149-155.

24. Li J, Shi R (2006) A device for the electrophysiological recording of peripheral nerves in response to stretch. J Neurosci Methods 154: 102-108.

25. Ichimura H, Shiga T, Abe I, Hara Y, Terui N, et al. (2005) Distribution of sodium channels during nerve elongation in rat peripheral nerve. J Orthop Sci 10: 214-220
26. Gallant PE (2000) Axonal protein synthesis and transport. J Neurocytol 29: 779-782.

27. Chevalier-Larsen E, Holzbaur EL (2006) Axonal transport and neurodegenerative disease. Biochim Biophys Acta 1762: 1094-1108.

28. Ström AL, Gal J, Shi P, Kasarskis EJ, Hayward LJ, et al. (2008) Retrograde axonal transport and motor neuron disease. J Neurochem 106: 495-505.

29. Iacobucci GJ, Rahman NA1, Valtueña AA, Nayak TK2, Gunawardena S1 (2014) Spatial and temporal characteristics of normal and perturbed vesicle transport. PLoS One 9: e97237.

30. Abe N, Cavalli V (2008) Nerve injury signaling. Curr Opin Neurobiol 18 276-283.

31. Rishal I, Fainzilber M (2010) Retrograde signaling in axonal regeneration. Exp Neurol 223: 5-10.

32. Siu D (2010) A new way of targeting to treat nerve injury. Int J Neurosci 120: $1-10$.

33. Hoffman PN (2010) A conditioning lesion induces changes in gene expression and axonal transport that enhance regeneration by increasing the intrinsic growth state of axons. Experimental Neurology 223:11-18.

34. Hall TM, Elvey RL (1999) Nerve trunk pain: physical diagnosis and treatment. Man Ther 4: 63-73.

35. Butler DS (1989) Adverse mechanical tension in the nervous system: a model for assessment and treatment. Aust J Physiother 35: 227-238.

36. Millesi H, Zöch G, Reihsner R (1995) Mechanical properties of peripheral nerves. Clin Orthop Relat Res : 76-83.

37. Bueno FR, Shah SB (2008) Implications of tensile loading for the tissue engineering of nerves. Tissue Eng Part B Rev 14: 219-233.

38. Georgeu GA, Walbeehm ET, Tillett R, Afoke A, Brown RA, et al. (2005) Investigating the mechanical shear-plane between core and sheath elements of peripheral nerves. Cell Tissue Res 320: 229-234.

39. Tillett RL1, Afoke A, Hall SM, Brown RA, Phillips JB (2004) Investigating mechanical behaviour at a core-sheath interface in peripheral nerve. J Peripher Nerv Syst 9: 255-262.

40. Topp KS, Boyd BS (2012) Peripheral nerve: from the microscopic functional unit of the axon to the biomechanically loaded macroscopic structure. Journal of hand therapy: official journal of the American Society of Hand Therapists 25142-151.

41. Topp KS, Boyd BS (2006) Structure and biomechanics of peripheral nerves: nerve responses to physical stresses and implications for physical therapist practice. Physical therapy 86:92-109.

42. Boyd BS, Puttlitz C, Gan J, Topp KS (2005) Strain and excursion in the rat sciatic nerve during a modified straight leg raise are altered after traumatic nerve injury. Journal of orthopaedic research? official publication of the Orthopaedic Research Society 23:764-770.

43. Franze K (2013) The mechanical control of nervous system development. Development 140: 3069-3077.

44. Ayali A (2010) The function of mechanical tension in neuronal and network development. Integrative biology? quantitative biosciences from nano to macro 2:178-182.

45. Cullen DK, Lessing MC, Laplaca MC (2007) Collagen-dependent neurite outgrowth and response to dynamic deformation in three-dimensional neuronal cultures. Annals of Biomedical Engineering 35:835-846.

46. Siqueira R (2007) Lesões nervosas periféricas: uma revisão. Revista Neurociências 15:226-233.

47. Fu SY, Gordon T (1997) The cellular and molecular basis of peripheral nerve regeneration. Mol Neurobiol 14: 67-116.

48. Sunderland S (1990) The anatomy and physiology of nerve injury. Muscle Nerve 13: 771-784.

49. Wood MD, Kemp SWP, Weber C, Borschel GH, Gordon T (2011) Outcome measures of peripheral nerve regeneration. Annals of anatomy Anatomischer Anzeiger?: official organ of the Anatomische Gesellschaft 193:321-33.

50. Chen ZL, Yu WM, Strickland S (2007) Peripheral regeneration. Annu Rev Neurosci 30: 209-233.

51. Novak CB, Mackinnon SE (1997) Repetitive use and static postures: a source of nerve compression and pain. J Hand Ther 10: 151-159. 
Citation: Santana HHS, Fernandes de Oliveira IAV, Medrado AP, Nunes Sá K, et al., (2015) Neurodynamic Mobilization and Peripheral Nerve Regeneration: A Narrative Review. Int J Neurorehabilitation 2: 1000163. doi:10.4172/2376-0281.1000163

Page 7 of 7

52. Lundborg G, Dahlin LB (1992) The pathophysiology of nerve compression. Hand clinics 8:215-227.

53. Brown CL, Gilbert KK, Brismee J-M, Sizer PS, Roger James C, et al. (2011) The effects of neurodynamic mobilization on fluid dispersion within the tibial nerve at the ankle: an unembalmed cadaveric study. The Journal of manual \& manipulative therapy 19:26-34.

54. Rempel D, Dahlin L, Lundborg G (1999) Pathophysiology of nerve compression syndromes: response of peripheral nerves to loading. J Bone Joint Surg Am 81: 1600-1610.

55. Burnett MG, Zager EL (2004) Pathophysiology of peripheral nerve injury: a brief review. Neurosurgical focus 16:E1.

56. Seckel BR (1990) Enhancement of peripheral nerve regeneration. Muscle Nerve 13: 785-800.

57. Shacklock M (2005) Clinical Neurodynamics. Elsevier.

58. Lundborg G (1988) Intraneural microcirculation. The Orthopedic clinics of North America 19:1-12.

59. Goulart CO, Jürgensen S1, Souto A1, Oliveira JT1, de Lima S1, et al. (2014) A combination of Schwann-cell grafts and aerobic exercise enhances sciatic nerve regeneration. PLoS One 9: e110090.

60. Greening J, Smart S, Leary R, Hall-Craggs M, O'Higgins P, et al. (1999) Reduced movement of median nerve in carpal tunnel during wrist flexion in patients with non-specific arm pain. Lancet 354: 217-218.

61. Greening J, Lynn B, Leary R, Warren L, O'Higgins P, et al. (2001) The use of ultrasound imaging to demonstrate reduced movement of the median nerve during wrist flexion in patients with non-specific arm pain. Journal of hand surgery (Edinburgh, Scotland) 26:401-406; discussion 407-408.

62. Greening J, Dilley A, Lynn B (2005) In vivo study of nerve movement and mechanosensitivity of the median nerve in whiplash and nonspecific arm pain patients. Pain 115: 248-253.
63. Dilley A, Odeyinde S, Greening J, Lynn B (2008) Longitudinal sliding of the median nerve in patients with non-specific arm pain. Man Ther 13: 536-543.

64. Mendell LM (2014) Constructing and deconstructing the gate theory of pain. Pain 155:210-216.

65. Moayedi M, Davis KD (2013) Theories of pain: from specificity to gate control. J Neurophysiol 109: 5-12.

66. Kim HK, Kerr RG, Turley CB, Evans PJ, Jay V, et al. (1998) The effects of postoperative continuous passive motion on peripheral nerve repair and regeneration. An experimental investigation in rabbits. Journal of hand surgery (Edinburgh, Scotland) 23:594-597.

67. Ip WY, Shibata T, Tang FH, Mak AF, Chow SP (2000) Adhesion formation after nerve repair: an experimental study of early protected mobilization in the rabbit. Journal of hand surgery (Edinburgh, Scotland) 25:582-584.

68. Lee WP, Constantinescu MA, Butler PE (1999) Effect of early mobilization on healing of nerve repair: histologic observations in a canine model. Plastic and reconstructive surgery 104:1718-1725.

69. Guntinas-Lichius O, Hundeshagen G, Paling T, et al. (2007) Manual stimulation of facial muscles improves functional recovery after hypoglossal-facial anastomosis and interpositional nerve grafting of the facial nerve in adult rats. Neurobiology of disease 28:101-12.

70. Udina E, Cobianchi S, Allodi I, Navarro X (2011) Effects of activitydependent strategies on regeneration and plasticity after peripheral nerve injuries. Annals of anatomy = Anatomischer Anzeiger?: official organ of the Anatomische Gesellschaft 193:347-53. 